\title{
偶発記憶に及ぼす項目間精緻化の効果
}

\author{
奈良教育大学 豊 田 弘 司
}

\section{Effects of between-item elaboration on incidental memory}

Hiroshi Toyota (Department of Psychology, Faculty of Educa-

tion, Nara University of Education, Takabatake-cho, Nara 630)

The present study was carried out to investigate the effect of between-item elaboration on incidental memory of words. Between-item elaboration refers to the encoding of relational information to each target item. Forty-four college students were asked to generate free associates to each target in the orienting task which was followed by unexpected recognition and recall tests. Triplets of targets which was known to elicit a converging associate were used. Targets of such a triplet were presented in massed or spaced fashion. Frequency of converging associates generated in the orienting task (free association) was used as an index of between-item elaboration. The proportion of targets correctly recalled for which the converging associates were generated was higher than that of the opposite cases. The above result suggested that the between-item elaboration was effective in retrieval of targets. No effect of types of presentation on free recall performance was observed.

Key words : free association, between-item elaboration, retrieval, incidental memory, free recall.

Jacoby \& Craik (1979) は, 精緹化 (elaboration) とは 記憶痕跡に情報を付加することと述べている．ただし， その付加される情報の中に他の記憶痕跡との弁別に関わ る差異的 (distinctive) な情報は含めていない(太田・原， 1980). しかし，一般には，精維化とは差異的な情報も含 めて記銘項目に情報を付加することであるとみることが できる(豊田，1987).

豊田(1987) は, 従来の精緻化研究を展望して, 精緻化 を2つの型に分けた. そこでの区別は, Hunt らの研究 (Einstein \& Hunt, 1980; Hunt \& Einstein, 1981; Hunt, Ausley, \& Schultz, 1986) によって主張された 2 つの情報すなわち関係情報（relational information）と 項目特殊情報 (item-specific information) の区別に対怘 するものである.すなわち，関倸情報は記銘語間のまと まりに関する情報であり，項目特殊情報は個々の記銘語 の差異性を高める情報である。そして，関係情報を付 加（符号化）する精緻化が項目間精緻化（between-item elaboration) であり，項目特殊情報を付加（符号化）する 精緻化が項目内精敉化 (within-item elaboration) であ る (Ritchey, 1980).

このように，精緶化研究は付加される情報の質を明ら かにしてきたが，方法論上の 1 つの問題があった．それ は，精維化の指標がないということである。記銘語に対 して上述したような関係及び項目特殊情報が確かに付加 されていることを示す指標がなければ，精敗化といら概 念は単なる説明概念の域を超えないであうう. Hunt ら
の研究でも, 方向づけ課題によって関係情報及び項目特 殊情報の符号化を方向づけてはいるが，雨情報が符号化 されていることを示す指標は設けられていない.そこ で，本研究では，方向づけ課題として記銘語からの連想 語を産出させるという自由連想課題を用い，以下に示す ような明確な精嗏化の指標を設けて，偶発記憶に及ぼす 精緻化の効果を検討する.

豊田 (1987) は，精徽化の指標として，記銘語からの連 想語に対する虚再認を提案しているが，本研究でも連想 語に対する虚再認を第 1 の指標として取り上げることに した. 項目間精緻化と項目内精緻化の区別をするなら ば，いくつかの記銘語に共通する連想語に対する虚再認 は項目間精緻化の指標であり, ある特定の記銘語に独 自の連想語に対する虚再認は項目内精緻化の指標といえ る. 項目間精緻化の指標としては, Ritchey (1980) が群 化量を提案しているが, 群化量江項目間精繳化がなされ た結果として生じる体制化の指標であり，関倸情報の符 号化すなわち項目間精縦化の指標としては不適切である (豊田, 1987). それ故, 本研究では, 豊田 (1987) に従い, 関係のある $3 つ の$ 記銘語(例えば，赤い，あざみ，植物） に共通する連想語(例えば，花）に対する虚再認を項目閒 精繳化の第 1 の指標として取り上げることにした。すな わち，記銘語の自由連想をさせることによって，産出さ

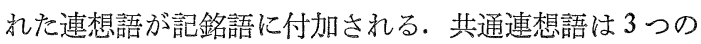
記銘語の関係情報にあたり，これに対して虚再認が生起 することは，関係情報の符号化つまり項目間精緻化が生 
じていることになるしかし，虚再認は生起頻度が低い という問題が指摘されている (Lindauer \& Paris, 1976)。 そこで，被験者自身が方向づけ課題 (自由連想)において 産出した連想語の中に共通連想語があれば，それを項目 間精緻化の第 2 の指標(産出された共通連想語) としてカ ウントし，虚再認に反映されない精緻化を取り上げよう とした.

したがって，本研究では上述したような 2 つ項目間 精緻化の指標を用いて, 正再生率との関係を検討するの であるが，2つの指標のそれぞれに対して以下に示すよ うな仮説が成り立つ.まず，第 1 の指標（共通連想語に 対する虚再認）については，再生された記銘語に対応す る共通連想語に対する虚再認の方が，再生されない記銘 語のそれよりも多くなるであろう。 また，第 2 の指標 （産出された共通連想語）については，共通連想語が産出 された記銘語の方が，産出されなかった記銘語よりも正 再生率が高くなるであろう。この 2 つの実験仮説を検討 するのが本研究の第 1 の目的である.

また，本研究では，関連ある 3 つ記銘語を連続して 呈示する場合と，そうでない場合の呈示形式の違いにつ いても併せて検討することにした. というのは，Puff （1966）に代表されるように，体制化研究において同じカ テゴリーに含まれる記銘語を連続的に呈示することによ って体制化の促されることが指摘されているからである (Gerjuoy \& Spitz, 1966; Kobasigawa \& Orr, 1973). 体 制化が促されるということは，記銘語間の関係情報が符 号化されていることになるから，関連ある記銘語を連続 して呈示すれば，それらの記銘語間に共通する情報（関 係情報)の符号化すなわち項目閒精緻化が促進されると 考えられるのである.したがって，関連ある記銘語を連 続して呈示する群 (連続呈示群)の方が, 非連続的に呈示 する群(非連続呈示群)よりも，項目間精緻化を反映して 記銘語の正再生率が高くなるであろう。この予想を検討 するのが，本研究の第 2 の目的である.

\section{方法}

被験者 専修学校の女子学生 44 名が実験に参加した. これらの学生の平均年齡は, 19 歳 7 か月 (18 歳 9 か月一 21 歳 5 か月) であった. なお, 連続呈示群及び非連続呈 示群に被験者の半数ずつが割り当てられた。

材 料 記銘語及びそれに対応する連想語の例が, Table 1 に示されている.これらの語は, 梅本 (1969) の 連想基準表から選ばれた，1一5文字からなるよく知られ た語である。連想語は，すべて基準表の最多連想反応も しくは次多反応語であり, 平均連想頻度は 16.54\% (共通 連想語は $18.19 \%$, 特殊連想語は $14.89 \%$ ) であった. 方 向づけ (自由連想) 課題で用いられる自由連想リストは, 上述の記銘語が 30 語及びリストの最初と最後のバッフ
Table 1

The examples of targets and their associates in the present study

\begin{tabular}{lcc}
\hline $\begin{array}{c}\text { 記銘語 } \\
\text { (targets) }\end{array}$ & $\begin{array}{l}\text { 共通連想語 } \\
\text { (converging } \\
\text { associate) }\end{array}$ & $\begin{array}{l}\text { 特殊連想語 } \\
\text { (specific } \\
\text { associates) }\end{array}$ \\
\hline 赤い & 花 & りんご \\
(red) & (flower) & (apple) \\
あざみ & & とげ \\
(thistle) & & (thorn) \\
植物 & & 動物 \\
(plant) & & (animal)
\end{tabular}

アー語が 2 語から成っていた。リストは， 2 種類つくら れた。連続呈示群用のリストは，共通の連想語をむつ関 連する 3 つの記銘語が連続して配列され，非連続呈示群 用のリストはこれらの関連する記銘語の間に他の記銘語 が介在するように配列されていた。これらのリストは, 1 語ずっ B 6 判の紙に印刷され，表紙をつけた小冊子に された. 挿入課題用紙は語識別検查の文字列を印刷した B 4 判の用紙であり, 自由再生テストの用紙は B 6 判の 大きさである. 再認テスト用紙は B 5 判で，記銘語 30 語の中からランダムに選ばれた 5 語, バッファー語が 2 語 (以上, 標的刺激), 共通連想語が 10 語, 各記銘語から 独自に連想される語（特殊連想語）が 25 語及びどの記銘 語とも全く連想関係のない語が 6 語が， 6 段階の確信度 評定尺度 (“確かにあった”から“確かになかった”) とともに印刷されていた.

手続き 実験は偶発記憶手続きを用い，被験者の所属 する専門学校の一室で集団的に実施された. (a) 方向づ け課題 まず，両群の被験者に対応するリストを配布 し, 実験者の合図にしたがってページをめくり，各ペー ジの印刷されている単語(記銘語)から連想される語を記 入するようにといら教示が与えられた．ただし，連想す る語の数は制限されなかった. 被験者は, 実験者の合図 にしたがって 20 秒ごとにページをめくり，記銘語から の連想語を記入していった. (b) 挿入課題 方向づけ課 題終了後, すぐに上述の挿入課題用紙を配布し， 3 分閒 の挿入課題を行った.この課題は，用紙に印刷された文 字列の中から 3 文字以上からなる名詞を見つけだして丸 印をつけるものであった. (c) 再認テスト 上述の再認 テスト用紙を配布し，再認テストを 5 分間実施した. 再 認テストでは，用紙に印刷された各語に対する記憶の確 信度に基づき，“確かにあった”から“確かになかっ た”までの6段階のいずれかに丸印をつけるように求 めた. また，被験者自身の連想した語と同じ語があれ ば，その語に丸印をつけるようにさせた（d）自由再生 テスト 上述した自由再生テスト用紙を配布し, 筆答に 
よる自由再生テストを 5 分間実施した。この際, 被験者 には先に呈示された小冊子に印刷された記銘語及びそれ から連想した語を，思いだした順に書くように教示され た.

\section{結果と考察}

方向づけ課題として用いられた連想リストの小冊子を チェックしたところ，ぞの被験者にも連想語の記入もれ はなかった，また，実験後，記銘の意図を持った者に挙 手を求めたが挙手はなく, 全員が記憶の意図を持たなか ったことが確かめられた。

共通連想語に対する虚再認 再認テストにおいて呈示 された共通連想語に対して“確かにあった”“あった と思う”及び“あったかむしれない”のいずれかの段 階に丸印をつけた場合を虚再認としてカウントした。し かし，この平均虚再認率は，連続呈示群が 9.09\%, 非連 続呈示群が $10.00 \%$ で予想以上に低かったので，虚再認 された共通連想語に対応する記銘語の正再生率と虚再認 されなかった場合のそれとの比較による実験仮説の検討 はなされなかった，上述したように虚再認は生起頻度が 少ないという問題が大きく反映されているので，生起頻 度を高める工夫をしないと指標としては適切でないとい える.

産出された共通連想語 30 の記銘語の内, 再認テス卜 において標的刺激として呈示された語 5 語を除く, 25 語 中，産出した連想語の中に共通連想語が含まれていた記 銘語数の平均は, 連続呈示群が 7.14 語 $(S D: 2.47)$, 非連 続呈示群が 7.64 語 $(S D: 2.75)$ であった。この共通連想 語が産出された記銘語数については, 両群間に差は認め られなかった $(t=.62)$. 連続呈示の方が非連続呈示より も項目間精繳化を促すことが予想されたが，虚再認と同 様，その傾向は認められなかった。

精緸化と正再生率の関係を検討するために，産出され た連想語の中に共通連想語が含まれている場合の記銘語 の正再生率と含まれていない場合の記銘語のそれとを比 較した. Figure 1 には, 両群に括ける平均正再生率が 示されている. この正再生率を角変換して, 2 (呈示形 式; 連続, 非連続) $\times 2$ (共通連想語産出; 有, 無) の分 散分析を行った. その結果, 共通連想語産出の主効果 $(F(1,42)=9.70, p<.01)$ のみが有意であり，連想語に共 通連想語が含まれている記銘語の正再生率が，含まれて いない場合のそれよりも高いことが示された。

この結果は，実験仮説を支持するものであった．すな わち，共通連想語 (関係情報) が符号化された場合には， 項目閒精緻化が生じ，記鉻語の検索が促進されることが 示されたわけである。従来の体制化研究や Hunt らの 一連の研究においても，関係情報の符号化が大切である ことが示されていた.しかし，この関係情報が符号化さ
れているという確かな指標を設けて検討し，その効果を 示したのは本研究が初めてであるといえる，従来の精緻 化研究の大きな問題点は; 精絲化すなわち記銘語に付加 される情報の指標がないことでめった. したがって，単 なる説明概念の域を超えなかったのであるが, 本研究に おいて精緻化と記銘語の正再生率を対応づけることがで きたといえよう。ただし, 本研究の場合, 再認テストが 自由再生テストよりも先に行われているために, 再認テ ストで呈示された語が自由再生テストでの検索手がかり になると考えられる。共通連想語は 3 つの記銘語に対応 しているので，1つの記銘語にしか対応していない特殊 連想語よりもその手がかりの有効性は高い。それ故, こ のような検索手がかりとしての有効性の違いが結果に反 映されているかもしれない。この点については, 自由再 生テストを先に実施するような手続きに扮いて，本研究 の結果が再現されるか不かを検討することが必要である う.

ところで, Hunt らによれば，その記銘語独自の項目 特殊情報の符号化の大切さが指摘されている。すなわ ち, Ritchey らの指摘する項目内精緻化である. 項目内 精緻化は, その項目独自の差異的な情報を符号化するこ とであるのだから, 共通連想語以外の連想語を被験者が 産出しているのであれば，そこには項目内精䤦化が生じ ているという見方ができる。そこで，全く連想語が産出 されなかった記銘語を除くすべての記銘語に対して項目 内精繳化が生じているとみなして, 共通連想語が産出さ れた場合とされなかった場合のそれぞれについて，再生 された記銘語及び再生されなかった記銘語に対応する共

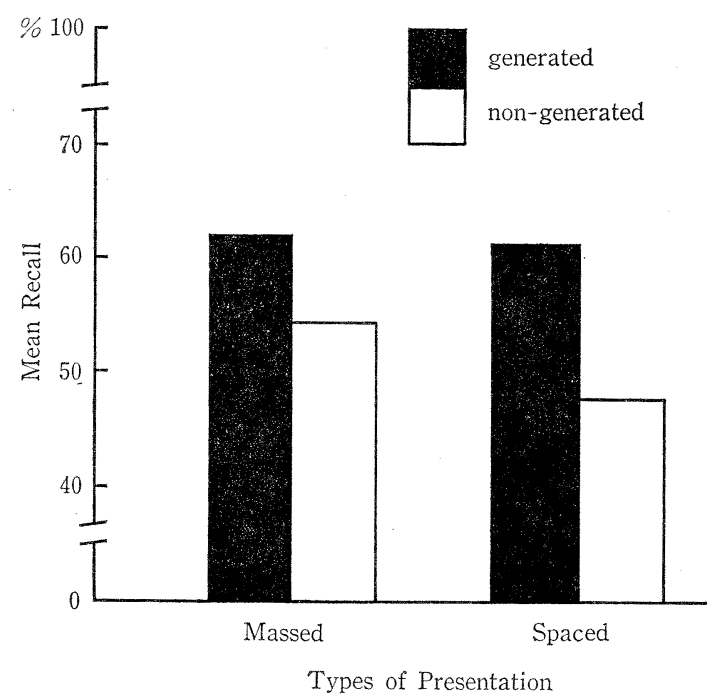

Figure 1. Proportion of targets recalled as a function of types of presentation for which a converging associates was generated or not. 
Table 2

Mean numbers of specific associates generated as a function of types of words (recalled and nonrecalled) when each converging associate was generated or not

\begin{tabular}{|c|c|c|c|c|}
\hline \multirow[b]{2}{*}{$\begin{array}{l}\text { Types of } \\
\text { presentation }\end{array}$} & \multicolumn{2}{|c|}{ generated } & \multicolumn{2}{|c|}{ non-generated } \\
\hline & recalled & $\begin{array}{l}\text { non- } \\
\text { recalled }\end{array}$ & recalled & $\begin{array}{l}\text { non- } \\
\text { recalled }\end{array}$ \\
\hline Massed & $\begin{array}{l}3.00 \\
(1.00)\end{array}$ & $\begin{array}{c}3.04 \\
(1.19)\end{array}$ & $\begin{array}{c}3.73 \\
(0.90)\end{array}$ & $\begin{array}{l}3.71 \\
(1.01)\end{array}$ \\
\hline Spaced & $\begin{array}{c}2.39 \\
(1.06)\end{array}$ & $\begin{array}{c}2.26 \\
(1.08)\end{array}$ & $\begin{array}{c}2.99 \\
(1.04)\end{array}$ & $\begin{array}{c}2.98 \\
(1.13)\end{array}$ \\
\hline & & & $\begin{array}{l}S D s \text { in } t \\
\text { parenthes }\end{array}$ & \\
\hline
\end{tabular}

通連想語以外の連想語数をカウントした. Table 2 に は，この平均值が示されている. この連想語数につい $\tau, 2$ (呈示形式) $\times 2$ (共通連想語産出; 有, 無) $\times 2$ (再 生, 非再生) の分散分析を行ったところ, 呈示形式の主 効果 $\left(F_{(1,42)}=5.81, p<.05\right)$ が有意であり, 連続呈示群の 方が非連続呈示群よりも共通連想語以外の連想語数すな わち項目内精緻化の程度が大きいことが示されたのであ る.しかし, 正再生率には両群間の差は見られなかった のであるから，本研究で扱った自由再生事態において は, 項目内精緻化は項目間精緻化よりも情報の検索にと っては效果的でないといえよう。

Hunt らは, 関係情報と項目特殊情報の符号化の重要 性を指摘しながら, 画情報の機能する検索過程の違いに ついても言及している(島田，1987).すなわち，彼らは， 検索過程が記銘語のまとまりの輪郭を描く（産出）過程 と，このまとまりの中から呈示された記銘語であったか 否かの区別をする(弁別) 過程から成っており, 関係情報 は産出過程に機能し, 項目特殊情報は弁別過程に機能す ると主張している, 本研究では自由再生事態を検討した のであるから, 検索過程としては, 産出と弁別の両方を 要する事態であったといえる.したがって, 産出過程に 機能する関係情報が符号化されなければ，項目特殊情報 がいくら符号化されたとしても記銘語の検索は難しかっ たのであろう.

さて, 本研究の第 2 の目的は, 呈示形式による効果を 検討することであった。しかし，連続呈示群が非連続呈 示群よりも正再生率が高くなるという予想は支持されな かった.ただし，この予想はあくまでも連続呈示した際 に項目精維化が促されることが条件であった。ところ が, 本研究では, 連続呈示群が非連続呈示群よりも項目 間精緻化の程度が高いということは，どちらの指標にお
いても示されなかったのである.したがって，両群間の 正再生率の差が見られなかったのは, 項目間精維化の程 度に差がなかったことに対応するものといえる.

\section{引用文献}

Einstein, G. O., \& Hunt, R. R. 1980 Levels of processing and organization: Additive effects of individual-item and relational processing. Journal of Expermental Psychology: Human Learning and Memory, 6, 588-598.

Gerjuoy, I.R., \& Spitz, H.H. 1968 Associative clustering in free recall: Intellectual and developmental variables. American Journal of Mental Deficiency, 70, 918-927.

Hunt, R. R., Ausley, J.A., \& Schultz, E. E. 1986 Shared and item-specific information in memory. Memory \& Cognition, 14, 49-54.

Hunt, R. R., \& Einstein, G. O. 1981 Relational and item-specific information in memory. Journal of Verbal Learning \& Verbal Behavior, 20, 497-514.

Jacoby, L. L., \& Craik, F.I.M. 1979 Effects of elaboration of processing at encoding and retrieval: Trace distinctiveness and recovery of initial context. In L.S. Cermak \& F.I.M. Craik (Eds.), Levels of processing in human memory. Hillsdale, N. J.: Lawrence Erlbaum Associates.

Kobasigawa, A., \& Orr, R. R. 1973 Free recall and retrieval speed of categorized items by kindergarten children. Journal of Experimental Child Psychology, 15, 187-192.

Lindauer, B. K., \& Paris, S. G. 1976 Problems with a false recognition paradigm for developmental research. Journal of Experimental Child Psychology, 22, 319-330.

太田信夫・原 聡 1980 処理水準の検討 筑波心理 学研究，2，99-109.

Puff, C. R. 1968 Clustering as a function of sequential organization of stimulus word lists. Journal of Verbal Learning and Verbal Behavior, 5, 503-506.

Ritchey, G.H. 1980 Picture superiority in free recall: The effects of organization and elaboration. Journal of Experimental Child Psychology, 29, 460474.

島田恭仁 1987 語の提示様式が関係情報と特殊情報の 符号化に及ぼす効果 京都短期大学論集，16，53-64. 豊田弘司 1987 記憶における精緻化 (elaboration) 研 究の展望 心理学評論, 30, 402-422.

梅本堯夫 1969 連想基準表 東京大学出版会

- 1990. 5.8.受稿, 1992.5.9.受理一 